\title{
O DESEJO E SEUS LABIRINTOS: REFLEXÕES ACERCA DO CINEMA CONTEMPORÂNEO
}

\author{
Henrique Codato ${ }^{1}$
}

\begin{abstract}
Resumo: Camille Dumoulié (2005) afirma que cada século apresenta um mito ideal próprio ao seu percurso histórico. Se a "ordem" foi o mito idealizador do século XVII e a "felicidade" o do século XVIII, o "progresso" serviu para fundamentar a história do pensamento no século XIX. Nesta perspectiva, o autor nos convida a refletir sobre qual seria o mito ideal que emerge em nossa época, e acaba por concluir que o do "desejo" é aquele que encobre o nosso tempo. Se a sociedade do espetáculo, tal qual apontada por Guy Debord (1997), faz com que nosso desejo se mova de lá para cá, sempre veloz, percorrendo todos os lugares e, ao mesmo tempo, faz com que ele escape por entre nossas mãos de forma fugidia e errática, parece-nos incoerente pensarmos o lugar do espectador de cinema sem questionarmos a natureza e a força do desejo que se apresenta em operação entre o filme e o exercício do olhar. As produções que escolhemos analisar encabeçam uma polêmica lista dos dez melhores filmes da década de 2000 lançada pela revista Cahiers du Cinéma. São elas: Cidade dos Sonhos (Mulholland Drive, David Lynch, 2001); Elefante (Elephant, Gus Van Sant, 2003) e Tropical Malady (Sud Palad, Apichatpong Weerasethakul, 2004). Assim, sistematizar um estudo dessas produções a partir da articulação entre desejo e olhar torna-se nosso principal desafio, a fim de, nesse gesto, revelar o que as três narrativas têm a dizer sobre o desejo em nossos dias.
\end{abstract}

Palavras-chave: Cinema contemporâneo, Desejo, Espectador, Psicanálise, Labirinto

Abstract: As Camille Dumoulié (2005) notices, each century presents its own ideal myth. If the "order" was the idealistic myth of the 17th century, the "happiness" crosses the 18th and the "progress" characterizes the 19th. In this perspective, Dumoulie infers that among all the myths of our time, the "desire" seems to be the paradigmatic one. As Guy Débord (1997) remarks, the Society of the Spectacle changes everything into objects of desire and transforms us as well into hungry and alienated spectators. It seems improbable or even impossible to think about the role of the spectator in contemporary cinema without interrogating the force and the nature of the film related to the desire of looking. Therefore, analyze some recent productions considering the articulation between desire and spectatorship becomes the main challenge of this paper. Elected by the magazine "Cahiers du Cinéma" as "the best movies of the decade 2000-2010", the works chosen are respectively Mulholland Drive (Lynch, 2001); Elephant (Van Sant, 2003) and Tropical Malady (Weerasetakhul, 2004). Developing a systematized study of these movies, we intend to investigate what they can reveal about desire in our days.

Keywords: Contemporary Cinema, Desire, Spectatorship, Psychoanalysis, Labyrinth

Camille Dumoulié (2005, p.08) afirma que cada século apresenta um mito ideal próprio ao seu percurso histórico. Se a "ordem" foi o mito idealizador do século XVII e a

\footnotetext{
${ }^{1}$ Doutorando da Universidade Federal de Minas Gerais (UFMG).
} 
"felicidade" o do século XVIII, o "progresso" serviu para fundamentar a história do pensamento no século XIX. Nesta perspectiva, o autor nos convida a refletir sobre qual seria o mito ideal que emerge em nossa época, e acaba por concluir que, entre os muitos "mitos que nos martirizam", o do "desejo" é aquele que encobre o nosso tempo. É extremamente difícil, contudo, delimitar o que entendemos por "nosso tempo" ou como "nossa época". Em certa medida, a arte dita contemporânea - e tratamos aqui da sétima entre elas - pode ser pensada nos moldes de uma lógica cultural que, ao apresentar uma crise das representações estéticas, desestabiliza o pensamento hegemônico. Tal desestabilização daria lugar ao provisório, à incredulidade, à pluralidade de paradigmas e, mais precisamente, ao descentramento do sujeito pela perda de um modelo identitário não mais único, agora fraturado, fragmentado, plural.

Se a sociedade do espetáculo, tal qual apontada por Guy Debord (1997), faz com que o desejo se mova de lá para cá, sempre veloz, percorrendo todos os lugares e, ao mesmo tempo, faz com que ele escape por entre nossas mãos de forma fugidia e errática, podemos sustentar a idéia de que desejo é movimento - uma pulsão, em termos psicanalíticos. Parafraseando JeanJacques Wunenburger (1997, p.35) o desejo "é o mais importante motor na produção de imagens irreais, cuja realização visaria satisfazer a própria faculdade de desejar do sujeito". Assim sendo, seria incoerente pensarmos o lugar do espectador de cinema sem questionarmos "a natureza e a força do desejo que se apresenta em operação na relação entre o filme e o exercício do olhar" (COMOLLI, 2008, p.136). Se essa mesma sociedade do espetáculo permite ainda um sem-fim de imagens, ela é, por outro lado, pouco propícia à sua análise, pois ao oferecer-nos o que Julia Kristeva chama de "estereótipos de nossos fantasmas" (KRISTEVA, 1992, p.107), ela nos privaria da possibilidade de criarmos cenários imaginários próprios. Aliás, é exatamente nessa privação que, segundo a autora, residiria o mal-estar contemporâneo, Tfouni e Silva (2008), fruto da relação do sujeito com seu próprio desejo (...) um nó entre realidade e fantasia ${ }^{2}$. Em suma, se o objetivo maior do sujeito é o de evitar o sofrimento, ele usa, para tanto, a realidade como fantasia para barrar o real.

As produções que escolhemos analisar encabeçam, de forma emblemática, uma polêmica lista dos dez melhores filmes da década de 2000, elaborada por dezesseis críticos especializados e publicada pela revista Cahiers du Cinéma em sua edição de janeiro de 2010.

\footnotetext{
${ }^{2}$ Sabemos que o desejo é sustentado pelo fantasma. Segundo a psicanálise lacaniana, as duas faces do fantasma articulam-se entre o gozo e o interdito. O sujeito ficaria dividido, separado do gozo, enquanto a pulsão ou o "desejo de" (LACAN, 1966, p.774) corresponderia à transgressão, o ponto de tensão entre ser e ter/não ter o falo. É a castração que mantém, juntos, o gozo e o interdito. Assim, o desejo se realizaria no fantasma, no sonho, no sintoma, mas de maneira incompleta ou ilusória. A fantasia, neste caso, seria a encenação no psiquismo da satisfação de um desejo que não pode ser saciado na realidade.
} 
São elas: A Cidade dos Sonhos (Mulholland Drive, David Lynch, 2001); Elefante (Elephant, Gus Van Sant, 2003) e Tropical Malady (Sud Palad, Apichatpong Weerasethakul, 2004). Notamos que estas obras, ao apresentarem uma narrativa fragmentada, fazendo emergir figuras como a do deslocamento e da descontinuidade em sua estrutura, possibilitam a manifestação de determinados sintomas que muito têm a dizer sobre a condição na qual se encontra o sujeito contemporâneo. A hipótese que levantamos é a de que estas narrativas, ao se firmarem no vaivém entre o limite e o ilimitado, entre a realidade e o sonho, entre o real e o imaginário, entre o mythos e o logos, convocariam o espectador de cinema a vivenciar uma espécie de estranhamento, fazendo-o oscilar, à deriva, entre o desejo de ser enganado e o de tudo saber.

Defendemos ainda a idéia de que estes filmes chegam à extremidade da experiência erótica que, em última instância, lembremos, não é o sexo, mas a morte, pois “é para as gratificações da morte, sucedendo e ultrapassando as de Eros, que toda busca verdadeiramente obscena se dirige" (SONTAG, 1987, p.64). O termo "obsceno" diz respeito àquilo que não pode ser "posto em cena" e o amor é obsceno em sua essência, diz Barthes (1977), porque coloca o sentimental no lugar do sexual. Assim, encontramos no desejo uma ambivalência pulsional e ontológica entre Eros e Thanatos, entre a vida e a morte. O desejo seria uma espécie de "fratura que apresenta o sujeito evanescente, que surge no lugar de uma ausência, sustentado pela busca de um reencontro com um objeto definitivamente perdido" (FRANÇA, 1997, p.197). Convidamos, pois, nosso leitor para, numa metáfora, adentrar conosco um "labirinto fílmico", não sem antes lembrá-lo de que o labirinto, na mitologia grega, é criação do engenhoso Dédalo para aprisionar o Minotauro - criatura metade homem, metade animal e serve como importante símbolo das figuras da descontinuidade e do deslocamento, portanto, do movimento. Em nosso ensaio, o labirinto foi justamente a alegoria que escolhemos para analisar, sob a égide do desejo, os três filmes propostos.

\section{As Figuras do Labirinto}

Gonçalo Villas-Boas (2003) explica que não se conhece ao certo o texto fundador do mito do labirinto, mas aponta uma série de fontes importantes para sua compreensão, como Eurípedes, Homero e Platão, além de Ovídio, cujos textos serviram de hipotexto para o mito. $\mathrm{O}$ autor afirma que “(...) o labirinto e o Minotauro fizeram parte integrante de um tipo de discurso negativo. O Minotauro era visto como uma representação e uma demonização do lado animal que há em nós, que os homens da luz querem combater" (VILLAS-BOAS, 2003, p. 03). Ora, tal como o mito, a estética do desejo, implícita no pensamento freudiano, é uma 
negatividade, afirma Maria Inês França (1997), pois apresenta "a dimensão da felicidade e da plenitude fora do plano da criação" (FRANÇA, 1997, p.139). Assim, não seria o minotauro o símbolo maior da imperfeição, da incoerência, reunindo o corpo desejante de um homem à cabeça de uma besta com chifres?

Voltemo-nos, pois, ao labirinto. Ele é um trajeto sinuoso ou tortuoso que apresenta impasses, bifurcações, falsas saídas na intenção de enganar aquele que se movimenta dentro dele. Seu objetivo maior é, justamente, o de fazer com que alguém se perca a partir das diversas possibilidades de caminhos que se desenham frente aos olhos; uma organização cuja complexidade torna difícil a missão de cernir inteiramente. Ora, não seria por acaso a escola de Elefante uma espécie de labirinto?

A este propósito, Alexandre Tilsky escreve:

Esse garoto-touro serpenteando nos labirintos lembra inevitavelmente o mito do Minotauro. A origem da representação. Retorno às fontes das lendas iniciáticas (e da arte parietal). Questionamento de Gus Van Sant sobre "Como evoluem os mitos e os contos hoje?", mas também "o que é uma imagem?" e "Como a juventude vive com as imagens?"; "Como eles são enganados pelas imagens como em um labirinto de signos?". Não é surpreendente, portanto, ver diversas cenas acontecerem num quarto escuro da escola: Gus Van Sant escruta precisamente a criação fotográfica e a imago $^{3}$. (TYLSKI, 2003)

O filme de Van Sant foi livremente inspirado por um curta-metragem homônimo feito na Irlanda do Norte, em 1989, por Alan Clark. O filme de Clark mostra uma série de assassinatos cometidos friamente e sem explicação, em sequências nas quais geralmente vemos o assassino perseguir sua vítima, atirar nela e fugir. Sabemos também que Elefante reproduz alegoricamente o que aconteceu em 1999 em Columbine, Estados Unidos. Porém, não há, no filme de Gus Van Sant, nenhum tom denunciatório, mas, antes, um desejo enunciatário. Ele não é sensibilizador, mas sensibilizante, parafraseando novamente Tylski (2003).

A camiseta amarela de John, batizado por Tylski como "garoto-touro", traz reproduzida a figura deste animal, delimitada apenas por sua silhueta, fazendo-nos pensar nos desenhos paleolíticos das grutas de Lascaux (FR). Lembremos também que John é a primeira personagem a nos ser apresentada e que, antes ainda de conhecermos seu rosto de anjo, o ouvimos discutir com o pai, bêbado, pedindo-lhe a direção do carro. O jovem precisa chegar à escola; ele precisa descobrir o que acontecerá antes de todos os outros; é ele quem deve avisálos da catástrofe, tal qual um anjo faria, salvando-lhes do mal. Não por acaso, os símbolos são

\footnotetext{
${ }^{3}$ Nossa tradução.In http://www.cadrage.net/films/elephant/elephant.html
} 
elementos caros a Van Sant. O diretor os utiliza na intenção de marcar suas personagens, revelando, através desses emblemas, seus respectivos destinos. O diretor já utilizara tal artifício em Gerry (2002), vestindo uma das personagens homônimas da trama - a que encontra a morte como fim - com uma camiseta que mostrava uma grande estrela amarela. De forma semelhante, enquanto Michelle, a garota estranha, feia e mal vestida é marcada ironicamente pelo signo do tigre, animal gracioso e encantador, Alex, o assassino, aparece com uma camiseta na qual se vê a figura do arco do triunfo, prenúncio, talvez, do sucesso de sua vingança. Há ainda o jovem de moletom esportivo vermelho, que traz nas costas a marca da cruz, símbolo da fatalidade anunciada que virá a cruzar o percurso labiríntico do filme.

As personagens de Elefante - que, lembramos, não são atores de verdade, mas estudantes escolhidos para atuarem no filme - nos são formalmente apresentadas por meio de suspensões temporais da imagem. Em seguida, passam a nos guiar por entre os corredores dessa escola-labirinto através de longos planos sequência que se esvaziam, perdendo-se na penumbra ou no excesso de luz. Por vezes a câmera flerta com as personagens de frente; por outras, estas se deixam acompanhar pelo olho da lente que se posiciona à altura de suas cabeças, registrando-as de costas. Portas se abrem e se fecham e jogos entre luz e sombra são construídos, dando um tom dramático ao filme. Árias de Beethoven - por vezes severamente cortadas por trechos de canções de rock ou por sons orgânicos amplificados - servem de fundo para as longas sequências construídas pelo diretor. Quando entramos, por exemplo, no quarto de Alex, vemo-nos tocar Para Elisa (für Elise) enquanto a câmera passeia por seu quarto, numa panorâmica giratória que visita todo o ambiente. Contudo, longe de qualquer tentativa de explicar ou justificar as ações do garoto assassino, a câmera de Van Sant provocanos um misto de náusea delirante e compaixão melancólica. E se a compaixão é uma forma de amor, lembramos que Para Elisa é uma mensagem do jovem Beethoven a uma moça chamada Thérèse Malfatti, a quem, então, pedira em casamento. Portanto, "uma declaração de amor acaba por deslizar ao longo deste filme, a priori tão frio", observa Tylski (2003).

Na mesma sequência, um jovem entra sorrateiramente pela janela e se instala na cama de Alex, assistindo-o tocar. Enquanto os dedos do assassino percorrem as teclas do piano, os do outro rapaz encontram as teclas de um computador. Há, então, um corte repentino no movimento da panorâmica, que retrocede para Alex ao piano, antes de, transmidiaticamente, nos lançar bruscamente dentro de um jogo de videogame, no qual a missão é a de perseguir e matar, num deserto, o que chamaremos aqui de zumbis virtuais. Presente, passado e futuro

\footnotetext{
${ }^{4}$ Nossa tradução.
} 
então se misturam e o tempo se suspende. Os dois assassinos finalmente se reconhecem; se aproximam: são cúmplices e amantes. Juntos eles esperarão o armamento encomendado por internet chegar e, como num rito de passagem, se banharão juntos, deixando-se levar (lavar) pelas mãos de Eros. "Eu nunca beijei ninguém", afirma um deles. Em seguida, os planos serão revisados, os detalhes minuciosamente checados - lembremos da cena que mostra o olhar de Alex perscrutando cada canto da escola -, e, ainda juntos, os dois invadirão a escola. Eles triunfarão, e se é por amor que o cúmplice segue cegamente seu mestre, é também por amor que o jovem mestre mata seu cúmplice cego. A sequência final do filme mostra justamente o encontro do assassino com um casal de namorados escondido numa câmara frigorífica. Alex aponta a arma contra os dois, - tal qual o cupido aponta suas flechas aos enamorados - e, sarcasticamente, hesita ao decidir qual deles deverá ser o primeiro a morrer.

Acerca do quarto escuro e da criação fotográfica, elementos que também figuram na citação de Tylski, Gus Van Sant se serve da personagem de Elias e de seu hobby, a fotografia, para refletir acerca do tempo e da relação do olhar com a imagem. Primeiramente, vemos o garoto fora da escola, buscando modelos para um exercício fotográfico. Ele encontra um casal e pede aos dois para fotografá-los. Ao fazê-lo, através de uma cena que nos remete diretamente a Depois daquele beijo (Blow up, 1966), de Michelangelo Antonioni, Elias aponta sua câmera para os apaixonados e aperta o dispositivo numa espécie de metáfora do que Alex faz com o casal na câmera frigorífica. Diz-se sempre, aliás, que a câmera aprisiona a alma das pessoas, congelando-as, e conhecemos amplamente a relação que a fotografia tem com a morte, explorada exemplarmente por Walter Benjamin, Roland Barthes e Susan Sontag. Um brilho comum aparece nos olhos atentos de Alex, ao atirar em suas presas, e nos de Elias, quando o estudante fotografa seus modelos. Essa fascinação segue o fotógrafo até o quarto escuro, onde a imagem se revela e ele pode, finalmente, admirar suas fotos. Como se procurasse algo além da imagem, todavia, Elias - nome do profeta bíblico que é arrebatado aos céus - volta seus olhos para cima, numa espécie de momento de quase epifania. É com frequência, aliás, que as personagens de Elefante olham em direção ao céu, onde tudo parece começar e acabar para Van Sant. Já na abertura do filme, vemos um poste de luz arranhar um céu azul brigadeiro; na metade do filme, um céu bíblico reaparece, anunciando a catástrofe que se abaterá sobre as personagens, enquanto a última cena do filme mostra o infinito novamente, dessa vez uma espécie de céu silencioso, simbolizando, talvez, o reestabelecimento da ordem. "So foul and fair a day I have not seen", nos dirá Alex,

\footnotetext{
5 “Um dia tão imundo e tão belo, eu nunca vi". Nossa tradução.
} 
parafraseando MacBeth. E a câmera, mais uma vez, gira numa panorâmica, tendo como centro gravitacional a imagem do garoto.

\title{
A Floresta dos trópicos
}

Em Tropical Malady, segundo filme que nos propusemos a analisar, Weerasethakul faz-nos visitar outro tipo de labirinto. Ele não é mais a complexa construção elaborada por Dédalo, mas toma agora a forma de uma floresta, lugar iniciático, por excelência, do xamanismo. A filósofa francesa Marie José Mondzain, em uma discussão acerca da perseguição no cinema ${ }^{6}$, comenta o filme tailandês:

\begin{abstract}
A savana e a floresta tropical não são como o deserto a céu aberto ou como os labirintos, perversamente estruturados e teorizáveis. Elas são compostas de um húmus originário e subterrâneo no qual o amante faz-se rio e fantasma, enquanto o amado torna-se presa espectral e consciente. O diretor constrói sua narrativa sob o signo enunciado do xamanismo. Seu filme não é, contudo, um filme folclórico ou etnológico. Ele segue outra dimensão, que interroga a função iniciática do próprio cinema num espaço erotizado ao extremo. Quando as tradições narrativas tornam-se gestos cinematográficos, o espectador, pela virtude da fascinação do olhar, entra no campo das metamorfoses e se encontra aspirado pelo buraco negro não simbolizável do território das origens. Trata-se do objeto que persegue o cinema quando este ambiciona produzir a figurabilidade do infigurável através de corpos aproximados no escuro, atentos, imóveis e mudos. (MONDZAIN, 2009)
\end{abstract}

$\mathrm{O}$ rio ou o fantasma, signos nos quais se transforma o amante ambivalente, tal qual aponta Mondzain (2009), servem de alegoria para a estrutura fílmica de Tropical Malady. A obra de Weerasethakul, na verdade, bifurca-se em duas narrativas distintas: enquanto a primeira delas retrata, de forma banal, os encontros e desencontros que acontecem entre o soldado Keng e o camponês Tong, o segundo relato reproduz essa "perseguição" a partir da enunciação de um conto mitológico cambojano que descreve um embate envolvendo um soldado e um tigre. Uma vez que o animal fora capturado e morto, o espírito vingativo de um xamã passara a encarnar na pele de um tigre durante a noite, assustando a todos os que vivem perto da floresta. As duas narrativas são, na verdade, versões de uma mesma história, na qual “o mito acaba por ser convocado pela modernidade, e não o contrário" (MONDZAIN, 2009). Somos levados, por assim dizer, para o outro lado do espelho, convidados a (re)assistir à primeira história, agora em seu regime de perseguição xamânico e de caça ao homem. Ora, sabemos bem que a iniciação xamânica é um tipo de morte. Ao caminhar pela floresta, o xamã tem de enfrentar os fantasmas dos mais diversos animais e, nessa espécie de luta

\footnotetext{
${ }^{6}$ Durante o Fórumdoc.bh 2009, em novembro de 2009.
} 
espiritual, conquista seus poderes, apropria-se de suas características, tal como acontece, como vimos, com as personagens de Elefante e seus respectivos símbolos. Com efeito, é a figura da metamorfose que aparece como fruto dessa perseguição entre caçador e presa, entre a câmera e o olhar. Mondzain (2009) nos recorda que o gesto cinematográfico é um ato de metamorfose na medida em que ele se ataca à discursividade e à continuidade da narrativa para fazer aparecer, de forma simultânea, as figuras da contradição e da reversibilidade do tempo. "Parece que o cinema veio mesmo, na modernidade, para ocupar o lugar dos ritos que negociam nossas relações com o reino do amor e da morte", afirma a filósofa.

Weerasethakul, contudo, não passa de uma narrativa à outra sem antes nos convocar a testemunhar uma despedida. Após flanarem por diferentes lugares - indo de uma feira popular a uma igreja budista construída nas pedras; passando por uma aula de aeróbica ao ar livre e por um hospital veterinário - Keng e Tong finalmente se separam. Na cena, o soldado toma a mão do camponês, beijando-a. Os dois trocam olhares apaixonados e, por sua vez, Tong toma a mão de Keng, mas ao invés de beijá-la, como fizera o amante, lambe-a faminto. A câmera mostra a saída de campo de Tong, ao mesmo tempo em que sua imagem é eclipsada pela escuridão da noite. Os dois homens só voltarão a se encontrar na floresta mítica, quando o soldado se hibridizará no tigre, transformando-se em uma criatura tal qual o Minotauro, metade homem, metade besta. Na sequência seguinte, o soldado, instalado no quarto de Tong, encontra uma foto do moço e, ao admirá-la - tal qual Elias fizera com seus retratos no filme de Van Sant -, ouve a mãe do campesino contar que um animal perigoso ronda a floresta e que os habitantes do vilarejo temem por suas vidas. "Eu vi uma pegada essa manhã e uma vaca desapareceu", diz a mulher. Repentinamente, como se o negativo do filme se rompesse, somos deixados numa escuridão completa e atravessamos o espelho, deparando-nos com outra, mas ainda a mesma, história.

A segunda parte do filme inicia-se com a imagem pictórica de um tigre, acompanhada de um texto que reproduz o conto cambojano. Ao dramatizá-lo, Weerasethakul nos mostra uma mulher aproximar-se de um soldado, pedindo-lhe ajuda. Como a floresta é perigosa e já faz noite, o homem decide acompanhar a mulher por entre as matas. Porém, ao segui-la, ele percebe uma cauda de tigre saindo-lhe pela saia. É neste momento que o soldado decide matar o animal-mulher, o que provocará a raiva e o desejo de vingança do felino-xamã. Ao analisar várias obras literárias, Freud (in FRANÇA, 1997, p.140) já constatara que onde quer que ocorra o tema da escolha, o mistério do feminino apareceria como o lugar mais desejado. França (1997) lembra, todavia, que "uma vez associado à morte, [o feminino] colocaria em jogo o enigma da semelhança, afirmando, por um lado, o real da Morte, desvelando o horror, 
e por outro, negando o real, ocultando-o e colocando em seu lugar o produto do desejo" (FRANÇA, 1997, p.140). Para o pensamento ocidental, fortemente marcado pela matriz cultural do cristianismo, o desejo acaba, pois, ganhando ares de catástrofe, e, uma vez reduzido a diabólicas libidos, não tem mais relação, como nos gregos, com o prazer e com o bem.

Os planos de Tropical Malady são não apenas bastante longos, mas muitas vezes tomam uma distância quase venerável em relação aos corpos filmados. Sua duração parece servir de medida para calcularmos o tempo que resta entre Tong e Keng. Os longos planos funcionariam como uma espécie de extensão do erotismo que envolve os dois jovens e, conseqüentemente, implicam também a imagem e o olhar do espectador neste prolongamento. Esse "cinema de fluxo", defendido por alguns, configura-se como uma possibilidade de novas construções temporais que apreendem o tempo como experiência, não como mero encadeamento linear/cronológico:

Mal dos trópicos insere uma segunda estória exatamente no momento em que o espectador também está envolvido com a sucessão de pequenos e fugidios fragmentos cotidianos que o casal dedica para seus encontros. Essa segunda estória prolonga o caráter de fascinação e mistério da primeira, fantasiando e reconfigurando a banalidade dos eventos de que constituem sua antecessora, tal qual os enamorados fantasiam os pequenos fatos cotidianos. (VIEIRA JR., 2009, p.10)

Como já fizera em Blisfully Yours (2002), Weerasethakul retorna mais uma vez à floresta, lugar para onde suas personagens geralmente partem em busca de alguma forma de transcendência. Há, em seus filmes, uma clara tentativa de cruzar as fronteiras e quebrar qualquer forma de dicotomia, seja ela entre a cidade e o campo, ou entre o espiritual e o material. Para ilustrar tal hipótese, lembramos que, logo no início do filme, vemos um grupo de soldados, andando em meio à floresta. Eles encontram o corpo de um homem desconhecido e, como fazem os caçadores com suas presas, carregam-no embrulhado num pedaço de tecido amarrado aos galhos secos de uma árvore. Ao fundo, num plano geral, identificamos um homem nu, que corre em direção às árvores como um animal. Mondzain (2009) defende que nesta sequência inicial - uma espécie de zona de contato entre as duas histórias -, identificamos, espalhados, todos os índices que, ao seguirmos, servirão como o fio de Ariadne para encontrarmos o sentido do filme. É especificamente essa zona de contato, $a$ priori incompreensível, que permitirá que as histórias encontrem um mesmo amálgama, fundindo-se e metamorfoseando-se em apenas uma narrativa que, também como o tricô de Ariadne, se desfaz quando a noite cai. 


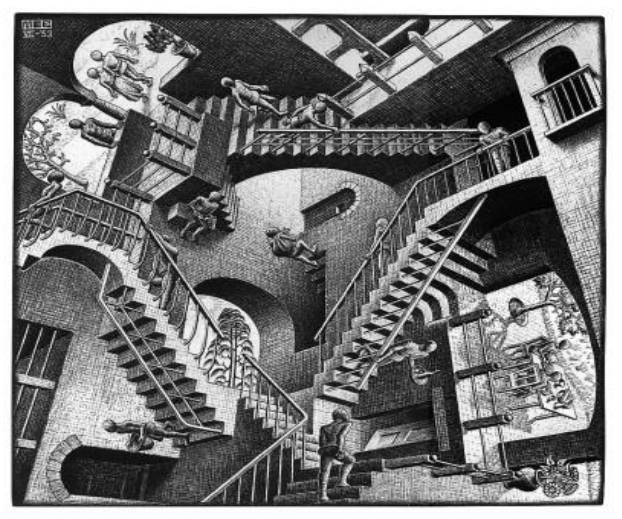

\section{A Relatividade labiríntica}

David Lynch, como supõe Mondzain (2009), parece mesmo ser o mestre do jogo cinematográfico que envolve a imagem e seu espectador. "Ele toca, de maneira exemplar, a dimensão xamânica do cinema, ainda que ela apareça como uma forma de artifício, a fim de guardar o poder sobre a miséria do espectador", diz a professora. Contudo, se a escola serviu de

labirinto para os olhos fascinados de Gus Van Sant, enquanto a floresta foi o espaço escolhido por Weerasethakul para o encontro do homem com o animal, Lynch serve-se do inconsciente como estrutura labiríntica para construir sua Cidade dos Sonhos. "O que aterroriza o indivíduo que vaga no labirinto é, mais do que a morte às mãos do Minotauro, a possibilidade de nunca sair dali, de passar o resto da eternidade vagando sem descanso por uma arquitetura sem sentido" (TAVARES, 2007, p.263). Mulholland Drive parece ser, pois, a estrada perdida que nos leva diretamente ao labirinto de Borges, este espaço infinitamente dizível; símbolo da perplexidade dos homens frente aos mistérios da vida, imagem do caos. Ou, ainda, quem sabe, a chave azul de Lynch abrirá uma das tantas portas secretas que escondem os labirintos, como este, pintado por M. C. Escher, e que passa, agora, a nos interessar.

A litografia, intitulada Relatividade (1953), mostra uma série de escadas distribuídas por toda a superfície do quadro, levando pessoas sem rostos aos mais diversos lugares de uma suposta casa. Ao mesmo tempo em que não há como precisarmos, ao menos com exatidão, o trajeto de cada um desses seres, há sempre uma porta, um vão, um portal, um vazio que se apresenta ao espectador como um possível destino para essas criaturas. Se olharmos com atenção, veremos que algumas dessas figuras sem identidade, esses zumbis - não mais virtuais, como no caso de Van Sant, mas, ainda assim, representações de nossos fantasmas sobem e descem os degraus das escadarias, levando, respectivamente, diferentes utensílios nas mãos. Um deles, localizado no canto inferior-esquerdo da obra, carrega uma espécie de bacia, seguindo em direção a um aposento fechado. Diametralmente oposto a este primeiro fantasma, no canto inferior-direito do quadro, vemos outro zumbi descendo os degraus, dessa vez, contudo, em direção a uma porta entreaberta. Ele leva na mão esquerda uma bandeja redonda, equilibrando sobre ela uma garrafa e um copo. Outros clones encontram-se ainda espalhados por todo o percurso que a obra reproduz, em meio às mais diversas atividades cotidianas. Um deles, por exemplo, tem por companhia um livro; outros dois estão à mesa, 
comendo. Escher consegue, a exemplo de seu servo-zumbi, equilibrar todos os elementos que figuram na litografia, de forma, justamente, a atingir um grau perfeito da simetria triangular desenhada a partir deles. Entretanto, uma pergunta nasce, imperativamente, do exercício de observação do quadro. De onde vêm e para onde vão as escadas desenhadas pelo artista holandês? Ora, se nos detivermos à imagem, descobriremos então absortos que as escadas são apenas trajetos para novas escadas. Seus degraus se encontram e se separam como se fizessem parte de um mesmo caminho, coexistem traçando linhas, construindo pontes que se configuram quase como os membros de um rizoma deleuziano. Analisando, entretanto, um pouco mais atentamente este triângulo eqüilátero que repentinamente surge da gravura do artista, avistaremos um terceiro fantasma que, curvado, carrega sobre os ombros um saco ou, se preferirmos, um fardo. Curiosamente, essa personagem que ocupa o centro da cena arquitetada por Escher, esse Atlas sem expressão que porta seu mundo nas costas, sai de uma espécie de sótão, que, para Jung, lembremos, servia como signo do inconsciente dito coletivo.

Voltemo-nos, por um instante, ao filme de David Lynch. A exemplo de Tropical Malady, a história do diretor americano também se bifurca, revelando uma segunda narrativa que, contrariamente à alegoria criada por Weerasethakul acerca do tigre e do soldado, não mais se utiliza de uma matriz mítica como origem, mas vai buscar no universo onírico seu núcleo de sentidos. A escolha do diretor pelo sonho como porto para ancorar sua história, justifica-se por seu papel ficcional, no qual a realidade e a ilusão não são mais identificáveis ou distinguíveis. Ou ainda, essa escolha poderia ser talvez explicada pelo status premonitório que tem o sonho, como se a primeira história fosse, assim, a manifestação de um desejo reprimido, uma espécie de sublimação da realidade da segunda trama. "Surge pois, a partir da Das Ding, a questão em torno de uma erótica que vai interrogar para-além da lei coercitiva do desejo, uma forma de transgressão cujo destino sublimatório da pulsão vai permitir sua fundamentação criativa" (FRANÇA, 1997, p. 190). É sobretudo a força sintomática dos sonhos que Lynch reinscreve no tecido fílmico, apagando qualquer traço de continuidade, e deslocando suas personagens para outro domínio. A sinuosa câmera de Lynch é sempre ameaçadora, perscruta as esquinas, e está pronta a enfrentar os monstros que saem de nossos mais íntimos pesadelos, tornando-os "reais". Toda a ontologia do diretor assenta-se na discordância entre a realidade, observada a partir de uma distância segura, e a absoluta proximidade do real, como infere astutamente Zizek (2005, p.48). A estética lynchiana é, desde o princípio, semelhante estruturalmente à fábrica de sonhos, tal qual descrita pela metapsicologia freudiana; um processo interminável e polimórfico, aberto e proteiforme. 
Na primeira das tramas, Betty, uma aspirante à atriz recém-chegada a Los Angeles, conhece acidentalmente uma jovem desmemoriada que assume o pseudônimo de Rita - uma homenagem à atriz Rita Hayworth - e de quem, aos poucos, se transforma em amiga. Seduzida pela misteriosa história de Rita, Betty decide mantê-la escondida no apartamento de sua tia, onde estava hospedada. As duas mulheres acabam de apaixonando, e, ao tentarem descobrir a verdadeira identidade de Rita, acabam encontrando uma grande soma em dinheiro e uma misteriosa chave azul. Já a segunda história, uma espécie de variação da primeira, inicia-se após uma inexplicável quebra na narrativa do filme, e mostra as mesmas personagens novamente, mas agora atuando em outros papéis. Diane chega a Hollywood depois de vencer um concurso de dança, disposta a se tornar atriz. Num teste de elenco, a moça conhece Camilla, de quem se torna amante. Entretanto, ao saber de outros casos que a moça mantém paralelamente, Diane trama seu assassinato, suicidando-se, em seguida, movida pela culpa e pelo remorso que a martirizam. Assim, se Weerasethakul nos convida a atravessar o espelho, a fim de que vivenciemos o mito, no caso de Lynch, a superfície que serve para refletir o duplo da história é turva e movente, profunda e densa. Estamos, talvez, no pântano lodoso de onde sai o barro viscoso que Keng, o soldado tailandês, passara no rosto para esconder-se (ou encontrar-se?) na floresta; aquele húmus "originário e subterrâneo", tal qual descreve Mondzain (remeto-me, aqui, à citação da filósofa acerca de Tropical Malady), início e fim de toda matéria humana.

No labirinto de Lynch - assim como no de Escher, para voltarmos à sua obra -, tudo é relativo, tudo se relaciona; tudo é referente. Todos os caminhos são, na verdade, um único caminho. Seu movimento desenha uma espécie de banda de Moebius, espaço topológico que serve aos estudos de orientabilidade, mas que Lacan adota como "primeiro marco de uma paixão pelos objetos que subvertem a representação comum do espaço, à maneira como o inconsciente freudiano subverte o sujeito" (RIVERA, 2008, p.32). Ora, "no hay banda" é o que repete a misteriosa voz, como um mantra, alertando-nos para o fato de que não é possível controlar nossos desejos. Tampouco é possível cernir ou compreender a lógica do inconsciente, pois ele é o palco das pulsões da personalidade, o reservatório da libido e da energia psíquica do sujeito, o sótão, de onde sai o morto-vivo escheriano, carregando, como um fardo, suas culpas e seus traumas. Não há mais minotauros nos labirintos de Escher e Lynch, e, assim como Rita não sabe quem ela é, nós, espectadores, não sabemos onde estamos, e somos, repentinamente, metamorfoseados em zumbis que descem e sobem as escadas construídas pelo diretor. Mas se desconhecemos nossa identidade, podemos, por outro 
lado, assumir aquela que nos pareça mais conveniente, aquela máscara que, só em nossos sonhos mais íntimos - pois é disso que tratamos aqui -, ousamos um dia vestir.

Stéphane Delorme (2010), ao comentar a eleição de Cidade dos Sonhos como o melhor filme da década, diz que o sujeito do filme é, na verdade, o amor. O fato de se apaixonar faz com que o medo da perda - sentimento pelo qual todos os afetos estão ameaçados, até o mais banal deles - saia da misteriosa caixa azul de Lynch - e, porque não dizer, do saco que carrega o fantasma de Escher - ressurgindo de forma desmesurada e incontrolável. Somos interpelados, então, por nossos desejos, de forma que “(...) nos arrepiamos, trememos, desaparecemos", diz Delorme. Mas "esses são 'mistérios do amor', como diz uma canção de Twin Peaks, que transfiguram tudo, engendrando as ficções mais fantásticas" (DELORME, 2010, p. 10). Como diria Kristeva na introdução de seu livro Histoires d'amour, todas as histórias falam de amor e nossas dores têm sempre como causa uma falta de amor, presente ou passada, real ou imaginária" ${ }^{8 "}$ (KRISTEVA, 1983, p.05). E, se pela última vez voltarmos nossos olhos para o quadro de Escher, no canto esquerdo da cena, vemos duas arcadas arredondadas se encontrarem, lado a lado, sugerindo um coração. Dentro desse suposto coração, nós acompanhamos o descompromisso de um casal de fantasmas, que, abraçado, parece então caminhar para fora do campo da litografia, abandonando o labirinto surreal do artista.

\section{Referências Bibliográficas}

BARTHES, R. Fragmentos de um discurso amoroso. Edições 70: Lisboa, 1977.

COMOLLI, J-L. Ver e Poder. Belo Horizonte: UFMG, 2008.

DEBORD, Guy. A Sociedade do Espetáculo. Rio de Janeiro : Contraponto, 1997.

DELORME, Stéphane. Mulholland Drive et après: Une décennie lyrique. Cahiers du cinéma n.652, Jan. 2010, p.10-11.

DUMOULIÉ, C. O Desejo. São Paulo: Ed. Vozes, 2005.

FRANÇA, M.I. Psicanálise, Estética e Ética do Desejo. São Paulo: Ed. Perspectiva, 1997.

KRISTEVA, Julia. Histoires d'amour. Gallimard : Paris, 1983. . Les maladies de l'âme. Galimard: Paris, 1992.

\footnotetext{
${ }^{7}$ Nossa tradução.

${ }^{8}$ Nossa tradução.
} 
LACAN, J. Os quatro conceitos fundamentais da Psicanálise. Rio de Janeiro: Jorge Zahar, 1985.

Des dispositifs pulsionnels. Paris: Galillé, 1972.

MONDZAIN, M-J. L’homo spectator. Paris: Bayard, 1997.

RIVERA, T. Ensaio sobre o espaço e o sujeito. Lygia Clark e a psicanálise. Ágora: Estudos em Teoria Psicanalítica. Vol.11 no. 2. Rio de Janeiro: UFRJ, July/Dec. 2008.

SONTAG, S. Contra a Interpretação. Porto Alegre: L\&PM, 1987.

TAVARES, B (org). Contos Fantásticos no Labirinto de Borges. Rio de Janeiro: Casa da Palavra, 2007.

TFOUNI, F.; SILVA,N. A modernidade líquida: o sujeito e a interface com o fantasma. USP, São Paulo : Revista mal-estar e subjetividade, 8(1), março de 2008.

TILSKY, A. Gus Van Sant et le Minotaure (Revista Cadrage.net, agosto de 2003). In: http://www.cadrage.net/films/elephant/elephant.html, em 24 de setembro de 2010.

VIEIRA JR., E. O tempo dos corpos no "cinema de fluxo" de Apichatpong Weerasethakul. Intercom - Sociedade Brasileira de Estudos Interdisciplinares da Comunicação - XXXII Congresso Brasileiro de Ciências da Comunicação - Curitiba, PR - 4 a 7 de setembro de 2009

VILLAS-BOAS, G. "O Minotauro e os Labirintos Contemporâneos". In Cadernos de Literatura Contemporânea 8/9: Literatura e Identidades, Orgs. Ana Luísa Amaral, Gonçalo Villas-Boas, Rosa Maria Martelo. Porto: Instituto de Literatura Comparada Margarida Losa, 2003, p.245-271.

WUNENBURGER, J-J. Philosophie des Images. Paris : PUF, 1997.

ZJZEK, S. La Subjectivité à venir: Essais critiques. Paris : Champs-Flamarion, 2006. 